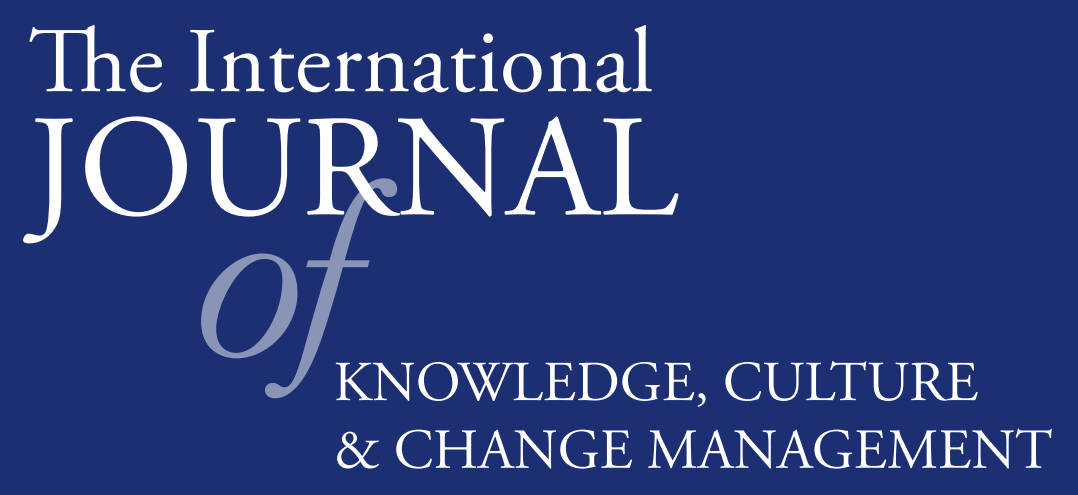

Volume 7, Number 2

A Comparison of Academic Staff Management Practices in Chinese and Australian Universities

Xiaoli Jiang, Xinhui Xu, Xiaoping Ma and Laurie Prosser 
THE INTERNATIONAL JOURNAL OF KNOWLEDGE, CULTURE AND CHANGE MANAGEMENT http://www.Management-Journal.com

First published in 2007 in Melbourne, Australia by Common Ground Publishing Pty Ltd www.CommonGroundPublishing.com.

(C) 2007 (individual papers), the author(s)

(C) 2007 (selection and editorial matter) Common Ground

Authors are responsible for the accuracy of citations, quotations, diagrams, tables and maps.

All rights reserved. Apart from fair use for the purposes of study, research, criticism or review as permitted under the Copyright Act (Australia), no part of this work may be reproduced without written permission from the publisher. For permissions and other inquiries, please contact <cg-support@commongroundpublishing.com>.

ISSN: $1447-9524$

Publisher Site: http://www.Management-Journal.com

THE INTERNATIONAL JOURNAL OF KNOWLEDGE, CULTURE AND CHANGE MANAGEMENT is a peer refereed journal. Full papers submitted for publication are refereed by Associate Editors through anonymous referee processes.

Typeset in Common Ground Markup Language using CGCreator multichannel typesetting system http://www.CommonGroundSoftware.com. 


\title{
A Comparison of Academic Staff Management Practices in Chinese and Australian Universities
}

\author{
Xiaoli Jiang, University of Ballarat, Victoria, Australia \\ Xinhui Xu, Shenzhen Polytechnic, Guangdong, China \\ Xiaoping Ma, Central Finance and Economics University, Beijing, China \\ Laurie Prosser, K.I.D.S. Foundation, Victoria, Australia
}

\begin{abstract}
This study investigated five Chinese higher education institutions in relation to management of academic staff. The study compared these practices with those used in three Australian universities. The results demonstrated that the Chinese universities provide more freedom to academic staff in terms of how staff spend their time at the university. However, there are more strict measures to control teaching staff's punctuality in attending their classes and to have detailed planning and teaching documentation. There are also additional teaching evaluations at both school and university levels, together with student evaluation. Chinese higher education staff management places greater emphasis on extrinsic financial rewards to improve staff performance than do their Australian counterparts. The income of Chinese academic staff is performance based and closely connected to their teaching, supervision, research and management workload. This approach initially came from the West and is now adopted by Chinese higher education management, reflecting Chinese socialist principles regarding income distribution. This measure of distribution is a very important motivational factor designed to enhance staff performance. This study provides an understanding as to the reasons why differences exist in management practices in China and Australia and offers some explanations from historical, political and social culture perspectives. This research identifies both positive and negative aspects of the two systems and suggests that learning good management practices from each other may bring positive changes to the productivity of higher education in both countries.
\end{abstract}

Keywords: Chinese higher education, Academic staff management, Australian Practices

\section{Introduction}

$\mathrm{S}$ INCE 1978, CHINA has embraced gradual economic reforms to modernise the country, to improve the quality of life for its people and to secure a better future for the country.

The reforms included cessation of traditional lifelong employment, so called "iron rice bowl", in the industry sector and many government agencies. Productivity has been greatly improved. However, at the same time, the system in the 1990s allowed academics working in the higher education sector to maintain an "iron rice bowl" and universities had no power to terminate staff employment. Faculty staff just needed to accumulate enough years and would be eventually promoted, never demoted. The status quo had spawned special interests and privileges which often led to a lack of creativity and productivity. Academics had little pressure to perform and departments were filled with people who had light workloads. Many generated large amounts of extra income via working for private universities or business. (Lin, 2005)

In the late 1990s, the Chinese government significantly increased the intake numbers of university students which resulted in an average increase in student enrolment of 30\% a year during 1998-2001. The universities have grown from an average size of 1,600 students to 6,000 students and classes that seat 30-40 students now accommodate more than 100. (Lin, 2005) There were 23 million university students by the end of 2005 (Zhou, 2006). China became the country with the highest number of university students in the world. The staff-student ratio reached nearly $1: 17$ by 2001 , a dramatic increase from a ratio of 1:3 in the early 1990s (Lin, 2005).

However, there are no Chinese universities listed among the top 100 universities in the world. As a result, there is a strong desire to have world-class universities in China. For example, over the next 15 years the Beijing University is aiming to join the world top 100 universities which are predominately western universities (Lin, 2005). To achieve this, there is an urgent need to improve the quality of higher education and the management of university staff. Westernization of Chinese universities, introducing competition and performance based reward systems appear to be on the rise. Learning different management approaches from different parts of the world is one of the major changes in Chinese higher education organisations. However, many of the

THE INTERNATIONAL JOURNAL OF KNOWLEDGE, CULTURE AND CHANGE MANAGEMENT, VOLUME 7, NUMBER 2, 2007

http://www.Management-Journal.com, ISSN 1447-9524

(C) Common Ground, Xiaoli Jiang, Xinhui Xu, Xiaoping Ma, Laurie Prosser, All Rights Reserved, Permissions: cg-support@commongroundpublishing.com 
management approaches adopted from the West have distinct Chinese culture characteristics.

One of the most important areas in Chinese higher education reform has been the breakdown of the old "iron rice bowl" mentality and improvements in academics motivation in their teaching, updating knowledge, producing high quality research outcomes and educating a new generation of welltrained, highly qualified labour force for global competition in science, technology, military and political spheres. The recent changes have steered academic staff to work much harder to advance the quality of their teaching and research productivity.

Australia is a country with a strong British influence. Its higher education system has many similarities with that of Britain. In addition, Australia has an individualism orientated culture (Hofstede, 2005). The higher education management ideology also reflects this cultural characteristic.

During this current era of globalisation and in the light of internationalisation of higher education, it is necessary to understand management practices from different countries particularly, those with very different cultural backgrounds. China is a country that has had enormous economic growth and is sending increasing number of students and academics to study in the West. Many have come to Australia. Further, many western degree courses are delivered in China. It is important for both Chinese and Australian higher education managers to understand what is happening in the other country in terms of their management practices of academic staff.

This paper compares current major management practices of academic staff in five Chinese higher education institutions with that of management within three Australian universities. It aims to present insights into their different approaches, the historical, political and social culture background underpinning the differences. It is hoped that the research will provide an in-depth understanding of the two systems and mutual learning opportunities.

\section{Methods}

\section{Document Analysis and Interviews}

Five Chinese higher education institutions (four universities and one TAFE college) were visited and 11 Chinese academic staff were interviewed regarding their perceived management practices of academic staff. Documents regarding academic code of conduct, rules and regulations, evaluation of teaching, teaching and research load, salary structures were collected.
Documentation from three Australian universities regarding their staff management policies, collective agreements, policies on employment conditions, unsatisfactory performance, promotions were downloaded from their internet sites. Three academic staff from the Australian universities were interviewed to gain insight into some of the management practices.

\section{Results and Discussions}

\section{Academic Staff Working Hours and Workload}

Academic staff in four of the five higher education institutions researched in China do not need to follow the rule of 8:00am-12:00, 2:00pm-6:00pm timetable for their administrative staff. All have very limited shared office space. Academic staff come in when they teach classes and when they have meetings. This is a common practice in universities in China. The system has been in place since the early days of the republic after the 1949 revolution. Only the TAFE college researched was the exception. According to a staff member at this college who complained about their strict timetable, it was the only higher education institution in China that requires staff to attend work from 8:00am-12:00 and 2:00pm to 6:00pm each day.

The interviews revealed that most Chinese academic staff take very little responsibility in course management, such as course coordination, answer prospective student inquiries, selection of new students, give approval for student graduation etc. These duties belong to the Department of Teaching Affairs within the universities. However, some academic staff do take students to the practicum part of their studies wherever appropriate such as schools, communities etc. Many academics also work as classroom teachers $^{1}$. Staff do research after teaching hours at their own home or at a library wherever and whenever they like. In addition, academic staff also have summer and winter holidays which amount to 6 and 4 weeks respectively. The teaching hours for the year to fulfill required workload varied between 54 hours to 432 hours in the five institutions. The four universities have the load capped at 288 hours. Only the TAFE institution researched has a load of 432 hours. The Chinese universities and TAFE institutions have 18 weeks in each semester. Therefore, the teaching load is $1.5-8$ hours per week for university staff, 12 hours per week for the TAFE college staff.

\footnotetext{
${ }^{1}$ In Chinese universities, enrolments in a particular course are usually organised into manageable classes. For example, one course has an intake of 120 students in one year. These 120 students are likely to be divided into three classes, approximately 40 students in each class. These 40 students comprise a group unit. They study and do many other activities together. A classroom teacher, normally an academic staff, is assigned to the group.
} 
In contrast, the Australian universities researched require their academic staff to attend work five days a week in their appointment letters and collective agreements. 20 working days of annual leave are available to all staff in addition to public holidays. However, in reality, many academic staff have allocated one day a week as their research day and they may not be visible in their office on that day. In one school of one of the universities researched, fulltime academic staff are require to teach between 11-12 hours per week in each of the 13 week semester. This is equivalent to $286-312$ hours of teaching per year, a similar teaching load in total to the Chinese. However, it is much higher per week than their Chinese university counterparts. In addition, many middle level academic staff in Australia are responsible for some management duties such as course coordination. It involves selection of students prior to each academic year, writing course documentations, answering prospective student inquires, advising students on their selection of units to fulfil course requirements, management of student enrolment, approve student graduation, involvement in courses committee and course review etc. The Australian academic staff's course management duties require them to be available for the students. As a consequence, they need to be in their office for most of the time during the week.

In China, students are required to enrol in a larger number of compulsory units; limited elective units are available. This makes their decision-making easier in terms of their selection of units and enrolment. Therefore, it is possible for the Department of Teaching Affairs within each university to manage enrolment. There is also a Recruitment Department to answer prospective students' questions. The number of students in each course is large, over 100 students in each intake in more than $70 \%$ of the courses at the five Chinese higher education institutions researched. Very few ourses with a small enrolment exist. All these make the centralised management of student recruitment, enrolment, and graduation possible in China. As a result, most academic staff do not need to be involved in course management as part of their work. This practice has allowed most Chinese academic staff to spend more time in their teaching and research activities.

By contrast in Australian universities, there are many small undergraduate courses which may have under 40 students in each intake. In one of the schools of the Australian universities researched, there were 6 undergraduate courses on offer, 4 $(66.7 \%)$ have an intake of under 40 each year. There are also many electives available, more flexibility in the course in terms of what units students may choose. Further, students often change courses and universities, take leave or withdraw from studies.
Cross institutions credit transfers are often required. Therefore it is desirable for a designated person who knows the course well to manage student affairs, interpret the course requirements and advise students in unit selections. Individual freedom of choice and recognition of individual needs are accommodated.

The different roles of academics in Australian and China reflect different cultural traditions, population and availability of resources. Australia is an individualist culture orientated society. In individualist societies, individual choice and freedom are emphasised (Triands, 1995). Many small courses in Australian universities are designed to suit individual student needs. Australia also has a small population. As a result, the number of students in each course is smaller than that in the courses in China. The small numbers, diverse course structures and more electives make it possible and maybe desirable for an academic to be the course coordinator managing the course and student affairs. However, a large amount of time is consumed in course management. There is less time for teaching and research. The large numbers in each course in China make central management possible and improve the efficiency of course management. In reality the management of courses by administrative staff free up the academic staff. Academic staff can be more effectively engaged in teaching and research activities. According to Australian National Tertiary Education Union (NTEU) (2000), administrative responsibilities have been identified as one of the major stressors for Australian academics within the workplace. A NTEU survey indicated that the average fulltime Australian female academics worked 51.9 hours per week, males 53.3 hours per week. This exceeds 10 hours in each working day.

\section{How is Financial Reward used as a Motivation Factor?}

One of the major socialist principles in relation to income distribution in China is "the more people work, the more they obtain financially", "distribution of income according to people's work". This principle is reflected strongly in current university staff payment and acts as an important part of staff management.

All Chinese higher education institutions researched have very detailed and complex payment formulas to reflect the years the staff worked, the level of their appointment, their teaching hours, the number of post graduate students supervised, their research publications/grants attained, together with other university work participated in such as observation and evaluation of staff teaching, supervision of student field work, military training and practicum etc. 

VOLUME 7

Approximately $1 / 2$ to $1 / 3$ of income of Chinese academic staff is contingent on the hours of their teaching, supervision and research outcomes. The hourly teaching rate is based on the income generating ability of the college/school or university, varying between $21-100$ yuan per hour. It would appear that all five institutions generate a large amount of money to pay their academic staff for their teaching. However, some institutions do pay their academic staff better than the others. For individual staff, the payment rate for each hour of their teaching is based on their level of appointment. For example, an associate professor is paid approximately $20 \%$ higher for each hour he/she teaches than that of a lecturer. Several of the Chinese staff interviewed teach up to 20 hours per week due to the financial rewards. It would appear there is considerable incentive to be promoted and teach more hours or do equivalent work.

Further, success in research and publications is directly connected to financial reward. The Chinese institutions researched all have a complex quantitative formula to calculate academic staff research achievement each year. The scores are calculated based on the level of the publication, e.g. AAA or AA or A or B... level of journals, the amount of words appearing in the publication, the rank as an author in the team, the research grant (including quantity and quality) obtained etc. For example, publishing a paper in an AAA national top level journal will give the staff a score of 300 points. If the staff can obtain a research grant as one of the National Natural or Social Sciences major projects, similar to an Australian Research Council (ARC) grant, the researcher could be granted up to 1,600 points.

In the five Chinese higher education institutions researched, each level of appointment has a publication target, e.g. a professor needs to accumulate a score of 200 points each year, associate professor 160 , lecturer 120 , assistant lecturer 60 etc. If the academic staff publish a paper, he/she will be rewarded financially according to the levels of publication, e.g. between 200- 600 yuan at the TAFE college, between 2,000-8,000 yuan at three of the four universities. However, if the academics cannot reach the target, they will be penalised. Depending on the institution, some are deducted in their research relevant allowances, others are demoted to a lower classification or increment. In the Chinese TAFE college, an associate professor could be demoted to a lecturer if he/she did not reach the target for two years. By using these rewards and penalties, the academics interviewed in this research were visibility feeling the pressure and expressed a great desire to improve their research publications.
In Australian universities, academic staff are paid according to their respective level of appointment. The levels are from A to E. There are 4 to 8 increments in each level except level E. Once staff reach the top increment of their respective level, further improvement in terms of payment comes from promotion via application by the individual. It would appear there is no direct connection between salary and hours of teaching, number of students staff supervise and publications. Only one university made a loose connection between the whole university staff performances and pay. In their collective agreement between the union and the university, it states: "additional salary increases equivalent to $1.00 \%$ of salary will be paid in the event that the University achieves:

1. a "top ten" national ranking in learning and teaching as assessed by the Commonwealth Learning and Teaching Performance Fund allocations for each of 2007 and 2008;

2. top rank status on at least three of the four indicators of National Research Competitiveness in each of 2006 and 2007; and

3. fee revenue growth of at least $\$ 21$ million a year in each of 2007 and 2008."

This is called an "Earning Esteem Incentive" payable to all eligible staff of the university.

There are workload meetings to balance staff workload in Australian universities. Equality is stressed amongst staff in terms of teaching hours, managerial duties and supervision load. For example, if a staff member is teaching a large unit with 200 students, there will be 17-20 hours of teaching per week required to cover both lecture and tutorials ${ }^{2}$. Once the standard teaching hours/load, e.g. 12 hours per week, is reached, the extra hours required in this unit will be taught by other staff members or sessional staff. Sessional staff are casual staff. They are normally post graduate students who take some tutorial teaching duties to supplement their income and gain work experiences. They are paid by the hours they teach. The hourly rate is much higher than the academics employed on a continuing base. However, there is little job security and other entitlements.

This system of payment is part of collective agreements struck between the Australian National Tertiary Education Union and the university managements throughout Australia. National collective bargaining provides a framework of pay scales and ensures some uniformity of practice across the sector. There are small incentives in terms of research publications and application for research grants. However, the money is to remain in the staff consultancy fund for research and work related use. Further, the

\footnotetext{
${ }^{2}$ This figure is calculated as two hours lecture per week and 1.5 hours tutorial per student in a tutorial group under 20 students.
} 
proportion of those incentives is very small in relation to staff salary, it is not sufficient to act as a major extrinsic motivator.

The Australian higher education system has evolved from the British university system, based on a consideration for a "liberal profession", academics are perceived to value and be capable of exercising considerable autonomy over macro issues such as governance and institutional direction. They are intrinsically motivated (Schwartzmann,1994). They regulate themselves and strike a bargain with society, providing advice to society in return for freedom from lay supervision. (Winstanly, Sorabji \& Dawson, 1995)

In recent years, Australian management has placed increased emphasis on performance-based remuneration to stimulate high performance and enhance productivity in the context of intensified global competition (Hanley \& Nguyen, 2005). This phenomenon is related to the equality theory (Adams, 1965). The theory suggests that pay satisfaction derives from how fairly employees see themselves as being treated in procedural and distributive terms relative to significant others within and beyond the organisations. The clearer the link between effort and reward, the fairer the perceived treatment, the greater satisfaction with pay. This theory implies greater pay satisfaction and a greater motivation effect where the relationship between effort and performance is transparent and the relationship between performance goals and pay is clear. (Kessler, Heron \& Gagnon, 2006)

The Chinese performance-related pay practices were learnt from the West after the reform. The "iron rice bowl" ideology and related egalitarian payment practices were dominant in Chinese higher education for more than 40 years. Academics did little research, their teaching load was low and there were no key performance indicators (Lin 2005). There was no clear connection between effort and financial reward; a lack of progressive spirit in the higher education sector was clearly evident at that time.

In this historical context, to break the "iron rice bowl" mentality, to improve productivity and to catch up with the world's elite universities, a more accountable system was required. It would appear that the Chinese performance-related pay practice is designed to achieve this in a bid to break from the past. It is a highly extrinsic motivated reward practice. The reward system was very carefully structured to encourage staff to teach more classes and conduct quality research in order to achieve excellence in higher education in China.

Most of the Chinese academics interviewed believed that the current reward system and management were fair. They acknowledged the intense pressure and competition. However, it was perceived that management was bringing the best out of the academics.

Although unions and performance-related pay are well-established institutions in the Australian labour market, they are based on stark contrasting ideologies and cultures. The first institution reflects the old notion of "collectivism" in industrial relations, while the second reflects "individualism" in the employment relationship, allowing individual remuneration to be tailored to individual performance. (Hanley \& Nguyen, 2005)

Marshall's (1998) and O'Donnell's (1998) examined the nature and scope of performance-related pay introduced in Australian federal and state public sectors and revealed that despite the growing popularity of performance-related pay, the design and implementation of these schemes was often poor. Critics of this reward approach often point to the divisive nature of the system. It is argued that paying staff in such a way has the potential to lower morale within the otherwise collegiate teaching profession, increase bureaucratic control, and lead to demotivation and add pressure among staff (Tomazin, 2007).

Given the perceived negative impacts, unions are resistant to the use of performance-related pay systems. Traditional union arguments against such measures are: work intensification and managerial control; erosion of collectivism; union exclusion and the rise of individual contracts. Incentive schemes may increase an individual's performance but they also introduce tension and stress, thus reducing satisfaction. (Hanley \& Nguyen, 2005). Higher education in Australia has traditionally been a union stronghold. In 2004, there were just over 33,000 full-time and fractional academic staff employed in Australia's higher education system, approximately 16,000 academics were members of the National Tertiary Education Union (NTEU) (Robinson, 2006). This explains one of the major reasons why in an individualist orientated Australian culture, a performancerelated pay system has not been fully implemented into the higher education sector. It would appear both positive and negative outcomes can derive from both Chinese and Australian higher education reward systems. The utilisation of their respective approaches is closely related to their historical, political and social culture context.

\section{Rules, Regulations and Penalties with regard to Punctuality in Relation to Teaching Classes and Supervision of Examinations}

In Chinese universities, it is evident that clear rules and regulations regarding a code of conduct for academics are in place for a strict control on punctuality of staff attendance in teaching and examinations. 
These rules, regulations and relevant penalties are published in hard copies and placed on university websites. Teaching incidents such as lateness for classes or missed classes are strictly forbidden. Universities documents reveal that there are three levels of teaching incident and related penalities:

The first level: the most severe incidents include missing a one hour class or late for class for more than one hour without a good reason; early release of examination content, examination paper was not prepared or completed by the time of the examination; the principal examination supervisor did not arrive on time for the examination; losing student examination results; examination supervisor did not take responsibility which led to many students cheating during an examination. Further, any content or language used in the classes against the Communist Party's Four Basic Principals are also categorised as most severe teaching incidents.

The penalties for this level of incident may involve publicly identifying the incident and the person responsible to the whole university/TAFE college, a warning as a disciplinary action, deduction of a whole year's bonus or teaching allowance and delayed promotion for two years.

The second level: moderate incidents. These include lateness for teaching classes between 5 minutes to 1 hour (one university is 15 minutes to 1 hour) without a good reason; without approval by the school, not teaching more than $1 / 4$ of the teaching content prescribed in the teaching outline designed by the department; due to lecturer's mistake in instruction or non appearance in class without approval, causing damage to university equipment or property or student injuries; change student examination results without approval.

This level of incident can result in publicly notifying the incident and the name of the responsible person to the whole university; deduct 3 months bonus or teaching allowance.

The third level: general/common incident. This level of incident includes the lecturer applying for leave, however, the manager not notifying students resulting in students waiting for more than 15 minutes; lecturer late for his/her class for 2-5 minutes (one university is over 5 minutes); due to examination papers not ready or the supervisor not attending the examination on time, the examination is delayed for 5-30 minutes.

This level of incident will result in publicly notifying the incident and the responsible person to the whole school, with a subsequent deduction of 1 month bonus or teaching allowance. In the TAFE college researched, the annual bonus for the whole school would be deducted by 50,000 to 100,000 Yuan (approximately $\mathrm{A} \$ 8,333-\mathrm{A} \$ 16,667$ ) in the event of any of the three levels of incident, an ex- traordinary amount of money in China. All staff in the school will share the pain and be paid less in their annual bonus.

The offender at all three levels will also need to submit a written self-criticism letter to the head of the school.

However, at Australian universities, no documents could be found explicitly revealing such detailed regulation in attending teaching, examination duties and relevant penalties.

The difference between these two very different ways of handling punctuality may be attributed to the reality that most Chinese academic staff are not required to stay on campus when they have no classes. Perhaps there is a need, from a Chinese management perspective, to ensure that academic staff do arrive on time for their teaching responsibilities. Clear regulations and severe punishments are effective ways of managing punctuality in Chinese culture. By comparison, most Australian academics normally have an office space and are required to be at work everyday. The possibility of being late for classes and examinations is not so great.

Chinese culture is high on collective national culture scales. There is a tendency for external control from a management perspective (Deresky, 2000). In China, clear regulations and related punishment are important management approaches to exercise control. Further, Chinese have a weak uncertainty avoidance culture. People in such cultures are more relaxed and less anxious. However, punctuality may not be emphasised (Hofstede, 2005). Late arrivals are common in business practices and even airline arrivals. To ensure teaching punctuality, it is necessary to implement strict measures. These measures appear to be effective. According to the interviewees and observations by the researchers, staff in the five Chinese higher education institutions were strictly following the regulation.

In contrast, in one of the Australian universities, according to the staff interviewed, some academics often arrive a little late for their lectures and tutorials, due partly to no clear penalty or accountability for these behaviours. It would appear punctuality has never become an issue at this university. Self-discipline is relied upon when managing time in Australia. Little external control is placed on academic staff in this perspective of their work.

\section{Evaluation of Staff Teaching}

In terms of management of teaching quality, different Chinese higher education institutions have slightly different assessment methods. However, all utilise a combination of student evaluation of teaching and senior professional panel evaluations. 
Normally, $20-40 \%$ of the evaluation marks come from students and 30-35\% from a panel comprised of senior academics within the university. They observe classes according to a set of criteria, checking teaching plans, lecture notes and mark the teaching accordingly. The other $30-35 \%$ of the marks come from another panel organised by the respective school/department. The Chinese TAFE college also implements peer evaluation, amounting to $20 \%$ of the total marks. The evaluations are conducted once a year.

In one Chinese university, the evaluation results are ranked against other staff within the university. In the case of all the Chinese institutions researched, senior management of the department and the university hold the results. According to their official documents, the evaluation results will have implications on financial rewards and penalties. Staff with excellent teaching marks are rewarded with certificate and money such as a bonus, or $20 \%$ increase in allowances. In the TAFE college, staff will be upgraded in increment. For staff who do not pass the evaluation, a yellow card is issued and marks will be deducted in the annual assessment. Furthermore, the hourly payment of teaching may be deducted by up to $50 \%$ at three of the four universities. At the remaining university all the university allowances would be withheld. In the TAFE college, the level of appointment will be dropped by one level. However, the deduction of salary may not be strictly implemented according to one of the interviewees from one university.

In Australian universities, it would appear student evaluation is the only evaluation of staff teaching and their experiences of staff supervision. There are other forms of evaluations/surveys such as quality of administrative and support services for students, graduate destination survey, and course experience questionnaire. They are all in the form of seeking student opinions in relation to the quality of the education they experienced. Observation by senior management in classes appears not to exist. Further, academic staff have rights not to disclose the results of student evaluation on their teaching. It would appear in Australia, a highly individualist country, evaluation and management of evaluation results are associated with individual rights and privacy. External interference is not encouraged (Heater, 1999).

Further, the purpose of evaluation is to provide feedback to the individual for further improvement. There are teaching awards both within the universities and nationwide within the higher education field. Staff can be nominated. Submissions of evidence of good teaching practices by the nominees are required. The rewards focus more on recognition and honour rather than financial.
Australian staff also experience performance appraisal with their supervisor once a year. Staff members are required to submit a portfolio and meet with his/her supervisor. A staff member's annual portfolio will comprise the following documents: an engagement profile; an achievement report, including teaching, research, managerial responsibilities and community work; a career development plan; and any supporting documentation relating to other formal processes in the university such as tenure, promotion, probation, etc. (where applicable). The supervisor and staff member will then meet at least annually to review the portfolio and to update it to reflect the work unit's plans and priorities for the forthcoming year. In this cycle, the outcomes from student evaluation of teaching do play an important role in demonstrating achievement of the staff in teaching.

According to the three Australian universities documents with regards to incremental increase, if staff performance is satisfactory the supervisor will recommend an incremental progression. If staff performance is unsatisfactory, the salary increment in salary will be withheld based on the supervisor's recommendation. However, it would appear this rarely happens in practice.

It is apparent that Chinese management of quality of teaching focuses on multiple levels of evaluations. Evaluations by the senior management form an important part. This practice reflects the large power distance of Chinese culture. In work and organisation, large power distance societies emphasise senior management control and authority. Similarly, in education, teachers are treated with respect and students are encouraged to be obedient (Hofstede, 2001). In this cultural context, it is quite remarkable progress to include student evaluation of a lecturer's teaching. Originally there was no evaluation at all in the 1980's. Only in the 1990's was senior management evaluation introduced to Chinese higher education.

In the five Chinese higher education institutions, all lecturers interviewed expressed their fear of being marked down by students. They articulated that they could not do anything to upset their students. Perhaps this is a start towards a student centred learning and students being treated as equals. Students are more empowered and trusted. A more equal relationship between lecturers and students may evolve and indeed be fostered.

Further, the multiple evaluations at Chinese universities place greater pressure on the teaching staff to perform via seeking innovative approaches and self advance in knowledge and skills. As a result, it is an effective way to extrinsically motivate staff to improve their teaching. However, in a liberal individualist culture dominated Australian society, indi- 

VOLUME 7

viduals have undeniable rights to privacy (Heater, 1999). It is one of the major reasons why there is no senior management evaluation taking place and all evaluation results are returned to the individual, not to senior management. The outcomes of the evaluation on teaching are always retained by the individual staff and disclosure of the results is totally subject to the individual's discretion.

\section{Conclusions}

This research revealed considerable differences between Chinese and Australian university management practices of their academic staff. It would appear that the Chinese universities provide more freedom to academic staff in terms of how staff spend their time at the university. However, there are more strict measures to control teaching staff's punctuality in attending their classes. There are also multiple staff teaching evaluations at both school and university levels, together with student evaluation. The evaluations have a more competitive nature and are connected closely to financial reward.

In contrast, the Australian higher education management approaches follow more closely a liberal individual ideology and trust an individual staff's ability to be responsible for their own behaviour in terms of punctuality in teaching. Staff are not evaluated by their senior management. However, staff administrative workload is much greater than their Chinese counterparts. This creates stress on Australian academics. Nevertheless, Australian academics receive a significant higher level of take-home income, approximately 6 times their Chinese counterparts annually salary. However, the prices of goods are much cheaper in China. The real purchasing power difference is much less than the 6 times in actual dollar terms.

The income of Chinese academic staff is closely associated with their teaching, supervision, research and management workload, reflecting Chinese social- ist principles regarding income distribution. This measure of distribution is a very important motivational factor designed to improve staff performance. Historically, breaking the "iron rice bowl" mentality has been a driving force for this approach. It attempts to ensure that people who work harder receive a greater financial reward. Politically, the communist party has learned from its past and adopted a socialist principle with Chinese characteristics. Culturally, these approaches are suited to Chinese collective culture, together with a large power distance. It would appear that Chinese academics have been motivated to improve the quality of their teaching and research.

However, some of the management practices used in China that appear to be motivational cannot be put into practice in the current Australian cultural context, such as senior management evaluation and comparison of evaluation outcomes amongst staff. It is also very difficult to implement performance related pay in Australian higher education sector given the organisational cultural background of universities and the current workplace agreement debate in the country. The Australian management approaches mainly rely on intrinsic motivation of staff, the exception being when staff seek promotion. However, if an academic does not seek promotion and has reached the top increment of his/her relevant level, it would appear little external control can be exercised under the current management system. Mediocrity could be a potential outcome.

This paper suggests that if Australian university managements are really concerned about staff workload, the Chinese practice of central management of courses, recruitment and graduation should be closely examined. It is apparent that Australian academics could better use their time to improve their teaching and research. Trained administrative staff could well accomplish the course management tasks.

\section{References}

Adams, J .S. (1965), "Inequity in social exchange", in Berkowitz, L. (Ed.), Advances in Experimental Social Psychology, Vol. 2, Academic Press, New York, NY, pp. 267-99.

Deresky, H. (2000). International management: Managing across borders and cultures. Reading, MA: Addison-Wesley.

Hanley, G. \& Nguyen, L. (2005). Right on the money: What do Australian unions think of performance-related pay? Employee Relations 27 ( 2 ), 141-159.

Heater, D. (1999). What is citizenshi p ? Cambridge, Polity Press.

Hofstede, G. (2001). Culture's consequence: Comparing values, behaviours, institutions, and organisarions across nations. London: Sage.

Hofstede, G. (2005). Cultures and organizations: Software of the mind. London: McGraw-Hill book.

Kessler, I., Heron, P. \& Gagnon, S. (2006). The fragmentation of pay determination in the British civil service: A union member perspective. Personnel Review 35 (1), 6-28

Lin, J. (2005) China's higher education reform and the Beida debate. Harvard China Review, Spring, 132-138.

Marshall, N. (1998), "Pay-for-performance systems: experiences in Australia”, Public Productivity \& Management Review, 21(4), 403-18. 
National Tertiary Education Union (NTEU), (2000), Unhealthy Places of Learning: Working in Australian Universities. Retrieved 18 March, 2007 from World Wide Web: http://www.nteu.org.au/policy/current/stress/upl/fullreport

O’Donnell, M. (1998), Creating a performance culture? Performance-based pay in the Australian public service. Retrieved $16^{\text {th }}$ April, 2007 from World Wide Web: http://www.cpsu.org.au/creating_a performance_culture.htm

Robinson, D. (2006). The status of higher education teaching personnel in Australia, Canada, New Zealand, the United Kingdom, and the United States. Education International. Retrieved $16^{\text {th }}$ April, 2007 from World Wide Web: http://www.ei-ie.org/highereducation/file

Schewardzman, S. (1994). Academics as a profession: What does it mean? Does it matter? Higher Education Policy, 7(2), 24-26.

Tomazin, F. (2007). Pay as you learn. The Age, $11^{\text {th }}$ April, p.13

Triandies, H. C. (1995). Individualism \& Collectivism. San Francisco: Westview Press.

Winstanly, D., Sorabji, D. \& Dawson, S. (1995) when the pieces don't fit: A stakeholder power matrix to analyse public sector restructuring. Public Money and Management, 15(2), 19-26.

Zhou, J. (2006) Evaluation of teaching is a critical approach in improving the quality of education. A speech by the Minister of Education, P. R. China on $19^{\text {th }}$ April, 2006, retrieved $6^{\text {th }}$ April, 2007 from World Wide Web: http://jwc.cufe.edu.cn/ypcj/index.asp.

\section{About the Authors}

Dr. Xiaoli Jiang

Dr. Xiaoli Jiang has diverse research interests in the areas of global migration and culture change, cross-culture self-esteem, self-esteem and well-being of Asian migrants, and children's self-esteem.

Asst Prof. Xinhui Xu

Shenzhen Polytechnic, China

Asst Prof. Xiaoping Ma

Central Finance and Economics University, Beijing, China

Dr. Laurie Prosser

K.I.D.S. Foundation, Australia 



\section{THE INTERNATIONAL JOURNAL OF KNOWLEDGE, CULTURE AND CHANGE MANAGEMENT}

\section{EDITORS}

Mary Kalantzis, University of Illinois, Urbana-Champaign, USA.

Bill Cope, University of Illinois, Urbana-Champaign, USA.

\section{EDITORIAL ADVISORY BOARD}

Verna Allee, Verna Allee Associates, California, USA.

Zainal Ariffin, Universiti Sains Malaysia, Penang, Malaysia.

Robert Brooks, Monash University, Melbourne, Australia.

Bruce Cronin, University of Greenwich, UK.

Rod Dilnutt, William Bethway and Associates, Melbourne, Australia.

Judith Ellis, Enterprise Knowledge, Melbourne, Australia.

Andrea Fried, Chemnitz University of Technology, Germany.

David Gurteen, Gurteen Knowledge, UK.

David Hakken, University of Indiana, Bloomington, Indiana, USA.

Sabine Hoffmann, Macquarie University, Australia.

Stavros Ioannides, Pantion University, Athens, Greece.

Margaret Jackson, RMIT University, Melbourne, Australia.

Paul James, RMIT University, Melbourne, Australia.

Leslie Johnson, University of Greenwich, UK.

Eleni Karantzola, University of the Aegean, Rhodes, Greece.

Gerasimos Kouzelis, University of Athens, Greece.

Krishan Kumar, University of Virginia, USA.

Martyn Laycock, University of Greenwich and managingtransitions.net, UK.

David Lyon, Queens University, Ontario, Canada.

Bill Martin, RMIT University, Melbourne, Australia.

Pumela Msweli-Mbanga, University of Kwazulu-Natal, South Africa.

Claudia Schmitz, Cenandu Learning Agency, Germany.

Kirpal Singh, Singapore Management University, Singapore.

Dave Snowden, Cynefin Centre for Organisational Complexity, UK.

Chryssi Vitsilakis-Soroniatis, University of the Aegean, Rhodes, Greece.

Please visit the Journal website at http://www.Management-Journal.com for further information:

- ABOUT the Journal including Scope and Concerns, Editors, Advisory Board, Associate Editors and Journal Profile

- For AUTHORS including Publishing Policy, Submission Guidelines, Peer Review Process and Publishing Agreement

\section{SUBSCRIPTIONS}

The Journal offers individual and institutional subscriptions. For further information please visit http://ijm.cgpublisher.com/subscriptions.html. Inquiries can be directed to subscriptions@commongroundpublishing.com

INQUIRIES

Email: cg-support@commongroundpublishing.com 